\title{
Isotope exchange between carbonate minerals and fluids at equilibrium and during mineral phase transformations at Earth's surface temperatures
}

\author{
ANNA HARRISON ${ }^{1}$, ERIC H. OELKERS ${ }^{2}$, JACQUES \\ SCHOTT $^{3}$, PASCALE BÉNÉZETH ${ }^{2}$ AND VASILEIOS \\ MAVROMATIS 4 \\ ${ }^{1}$ Géosciences Environnement Toulouse (GET) - CNRS \\ ${ }^{2}$ Géosciences Environnement Toulouse-CNRS \\ ${ }^{3}$ GET-OMP-CNRS-Toulouse University \\ ${ }^{4}$ Géosciences Environnement Toulouse (GET)-CNRS \\ Presenting Author: anna.harrison@queensu.ca
}

The isotopic composition of carbonate minerals (e.g., C, O) is widely used as a record of conditions at the time of mineral formation. These isotopic compositions may also be used to trace the efficacy of engineered $\mathrm{CO}_{2}$ storage in carbon dioxide removal (CDR) strategies. However, the robust interpretation of the isotopic composition of minerals requires that the mechanisms of isotope fractionation are known. In addition, the isotopic composition of the mineral at the time of formation must be preserved over long timescales. Textural evidence of recrystallization can be used to indicate lack of preservation of isotopic compositions, but experiments have revealed that certain minerals may be subject to isotope exchange with their surrounding fluid without any obvious morphological changes $[1,2]$. We have explored the behavior of $\mathrm{Mg}, \mathrm{C}$, and $\mathrm{O}$ isotopes between fluids and various carbonate minerals both at chemical equilibrium and during mineral phase transformations. A series of experiments examining $\mathrm{Mg}$-carbonate mineral phase transformations revealed that $\mathrm{Mg}$ and $\mathrm{C}$ isotopic compositions of the minerals were substantially altered during transformation from a less to more stable hydrated Mg-carbonate. Similarly, a series of experiments that exposed calcite to a fluid at chemical equilibrium but spiked with ${ }^{13} \mathrm{C}$ and ${ }^{18} \mathrm{O}$ revealed isotopic exchange between the fluid and solid at $25^{\circ} \mathrm{C}$ over 4-7 months. The experiments revealed that up to $\sim 0.3 \%$ of the $\mathrm{C}$ in the solid was exchanged, though the rate and extent of isotope exchange was strongly dependent on the calcite-liquid surface area. Scanning electron microscopy revealed no significant changes in calcite morphology. The results of these experiments confirm not only that isotope exchange in calcite can occur without any visible evidence of recrystallization, but that elements can continuously exchange between fluid and solid without net dissolution or precipitation occurring. Together, these studies provide insights into mechanisms of isotope exchange between fluids and carbonates with important implications for the application of isotopic compositions of carbonate minerals to understanding past environmental conditions and tracing efficacy of CDR.

[1] Gorski and Fantle (2017) Geochim. Cosmochim. Acta 198, 439-465; [2] Oelkers et al. (2019) Chem Geol 512, 1-10. 